\title{
Implementation difficulties of advanced techniques in gynecological laparoscopy
}

\author{
Frank Willem Jansen • Wendela Kolkman
}

Received: 19 March 2008 / Accepted: 21 March 2008/Published online: 20 May 2008

(C) The Author(s) 2008

\begin{abstract}
Laparoscopic surgery has developed into an important part of the gynecological surgical pallet. Its implementation into daily practice has shown to be complex, especially the advanced procedures. The difficulties of implementation is multifactorial; however, the training of laparoscopy is one of the major issues of this subject. The adequate training of residents and gynecologists is essential for its optimal and safe implementation. Concerning the advanced procedures, the question raises as to who should be able to perform these procedures and how this is established. Causes, difficulties, and limitations of the implementation of advanced laparoscopy will be discussed in this paper.
\end{abstract}

Keywords Laparoscopy · Training · Advanced procedures · Implementation

\section{Introduction}

In fact, it was two centuries ago that Phillip Bozzini in Vienna introduced the possibility to view the inside of a hollow organ (i.e., the uterus) with a light transmitter containing an ordinary wax candle, called the Lichtleiter. Nowadays, due to technical innovations, it is not only possible to perform diagnostic procedures, but even advanced keyhole surgery. However, still, Bozzini's assumption that "surgery will not only develop new and previously impossible procedures, but uncertain opera-

F. W. Jansen $(\bowtie) \cdot$ W. Kolkman

Department of Gynecology, Leiden University Medical Center,

P.O. Box 9600, 2300 RC Leiden, The Netherlands

e-mail: f.w.jansen@lumc.nl tions which depended on luck and approximation will become safe under the influence of direct vision, since the surgeon's hand will now be guided by his eyes" is still actual [1].

Some considered endoscopic surgery as one of the success stories of the past century. However, Cuschieri and Shapiro [2], in 1995, wrote that it was "... the biggest unaudited free-for-all in the history of surgery," whereas Johnson, two years later, classified laparoscopic surgery as an "... expensive luxury, rather than a surgical revolution" [3].

Although indications to perform laparoscopic surgery are well established now, general surgeons perform laparoscopic cholecystectomy in $85 \%$ of the cases, whereas $30 \%$ of all ectopic pregnancies is still performed by laparotomy.

The more simple laparoscopic procedures are well implemented in daily practice and a significant increase of level 2 procedures (Table 1) is found. In the Netherlands in 2004, advanced laparoscopy counted for only $18 \%$ of all laparoscopic procedures. Nationwide, the laparoscopic approach of hysterectomy for benign indications is only $4 \%$ of the cases, whereas $52 \%$ is still performed by laparotomy [4]. Although it can be stated that the diffusion of operative procedures in the Netherlands has increased over the past decade, the acceptance, in general, is still limited, especially for laparoscopic hysterectomy and other more advanced laparoscopic procedures, such as sacro-colpopexy and oncological procedures.

Laparoscopic surgery has developed into an important part of the gynecological surgical pallet. However, its implementation into daily practice has shown to be difficult [5-7]. Causes, difficulties, and limitations will be discussed in this paper. 
Table 1 Endoscopic procedures stratified by level of difficulty (levels 1-3) according to the Royal College of Obstetricians and Gynaecologists (RCOG) [25]

Laparoscopy

Level 1

Diagnostic laparoscopy

Tubal patency tests

Sterilization

Level 2

Minor adhesiolysis

Ectopic pregnancy

Mild endometriosis

Cystectomy

Salpingo-oophorectomy

Tubectomy

LAVH without significant associated pathology

Sub-total hysterectomy without significant associated pathology

Level 3

Myomectomy

Major adhesiolysis with associated pathology

Total laparoscopic hysterectomy

Endometriosis (stages III and IV)

Incontinence procedures

Suspension procedures

$\mathrm{LAVH}=$ laparoscopic-assisted vaginal hysterectomy

\section{Difficulties of implementation}

One of the major difficulties of implementing advanced procedures is the fact that most of the gynecologists in The Netherlands were not taught in this field of surgery. An inquiry among Dutch gynecologists who finished residency between 1998 and 2002 (response rate of 82\%) showed that $73 \%$ of the respondents performed basic laparoscopic procedure. [8]. However, $82 \%$ of the respondents did not perform any advanced laparoscopic procedure at all. According to the respondents, the causes and difficulties in implementing advanced procedures was the "long operating time." In addition, the fact that there was "too little attention for laparoscopy in residency" attributed to these difficulties. Financial or health insurance factors, or the assumption that laparoscopy was a hobby, were not considered to be a cause of the slow implementation.

A survey among surgeons in Canada has shown that many respondents were not interested in incorporating the advanced laparoscopic procedures into their daily practice [9]. Another survey among surgeons in the UK has shown that only $10 \%$ wanted to incorporate advanced minimally invasive surgery (MIS) into their surgical pallet, whereas the rest were better convinced with their activity in open surgery [10]. Unfortunately, many surgeons who are interested in advanced laparoscopy are still dealing with their own learning curves. This takes surgical procedures away from the residents' educational program [9]. Addi- tionally, residents have little opportunity to perform an advanced procedure as a primary surgeon and, therefore, graduate without enough skills to implement advanced laparoscopic surgery in their daily practice.

\section{Gender}

The decrease in residents' working hours [11], as well as the smaller number of major gynecological procedures performed in general [12], leads to less exposure in the operating room and to a relatively smaller case volume for residents in training [13]. Furthermore, the percentage of women in our speciality has increased over the last few years.

The question rises as to whether there is an effect of gender on the implementation of new surgical techniques. This subject has not been studied yet. However, studies have shown that men score themselves significantly higher on a Likert scale (scale $1-5 ; 1=$ not competent, $5=$ very competent) than women when they were asked how competent they felt with performing laparoscopic procedures $[14,15]$. We have to stress here that these studies showed the self-perceived competence and not the competence that they actually have.

In general, men are thought to be more skillful than women. Are men, therefore, more competent in laparoscopic procedures? Grantcharov et al. [16] showed that no statistically significant difference existed between male and female residents in terms of error or economy of motion scores when their performance was compared on a virtual reality simulator.

We feel that it is the women's false modesty that makes them score themselves lower than men, since men, in general, do not suffer from this phenomenon. Additionally, the question rises as to whether it is this false modesty that makes women hesitant in taking up new surgical techniques into their daily clinic. Unfortunately, the current studies do not answer this question.

\section{Limitations and perspectives}

The lack of structured training during residency may be the major limiting factor in the implementation of advanced laparoscopic surgery into daily practice. Gynecologists in teaching hospitals are still dealing with their own learning curves, which results in the lack of opportunities to be the primary surgeon during residency. Consequently, in this same context, there is a lack of laparoscopic case load and a lack of appropriate patients [8]. To enhance the implementation of more advanced procedures, several options are possible. As a practicing gynecologist, it does not give 
enough effort to accelerate the implementation by visiting congresses and courses or partake in simulator training to improve their skills. To teach advanced laparoscopic procedures yourself is, however, not an uncommon phenomenon $[17,18]$. It is questionable as to how advanced laparoscopic procedures can be safely introduced without compromising the patient. Hiring a laparoscopic expert to perform advanced procedures in your clinic has shown to be a safe and effective manner to accelerate implementation [18]. In general surgery and urology, a mentor traineeship has been shown to increase laparoscopic caseload and to have a positive effect on laparoscopic education and research $[17,19]$. In this mentor traineeship, the mentor is a laparoscopic expert, who teaches the trainee laparoscopic skills and procedures. This is preferably done in the trainee's clinic. This way, the trainee's operating team can be familiarized with the procedure and equipment, and more awareness is created of indications, contra-indications, and possible complications. Although it is well known that the complications rate increases when more advanced endoscopic procedures are performed [20-22], a prospective study designed by Kolkman et al. showed, in an observational study on mentor traineeship, that the implementation of more advanced procedures accelerated, whereas the mentor traineeship protects the patient from complications and conversion. The long operating times of advanced laparoscopic procedures are often subject to criticism. In this study, it was shown that the mentor traineeship did not prolong the operating time for laparoscopic hysterectomy [18].

Unfortunately, a mentor traineeship has its limitations, because it is a time-consuming educational program. If we consider that the learning curve for most laparoscopic procedures is still unknown, the question arises as to when a mentor traineeship is completed. The competence of the trainee can be objectively measured by an objective performance scoring system, such as the Objective Structured Assessment of Technical Skills (OSATS). This system is based on a global rating scale and has shown its reliability and validity, and is of value in conjunction with simulator assessment [23]. Until the learning curves are established, the OSATS system is an excellent alternative to objectify surgical skills.

As useful as animal laboratories are for in vitro training, there are many reasons for why they are not fully integrated into most surgical curricula. Ethical issues regarding the use of animals for training and studies are not to be discounted, but for most programs, the cost issues are prohibitive. There are substantial costs associated with maintaining specialized facilities and providing the appropriate staff [24].

Another question is whether or not all gynecologists should be able to perform advanced endoscopic procedures [25]. It is our opinion that all gynecologists should be able to perform level 1 and level 2 procedures (Table 1), with laparoscopic hysterectomy as an exception. Hysterectomy is the most frequent, major surgical procedure performed by nearly all gynecologists [12] and patients' demand for the minimally invasive approach for hysterectomy is increasing. Therefore, every hospital (teaching and non-teaching) should be able to offer this specific procedure. To implement this, every department of gynecology should dispose of one or two laparoscopic skilled gynecologists in order to be able to establish an internal referral system for laparoscopic hysterectomy. In an internal referral system 'open' gynecologists can refer patients with an indication eligible for the laparoscopic approach to their skilled colleagues for a laparoscopic hysterectomy. An internal referral system will build a bridge between abdominal and vaginal hysterectomy on the one hand, and laparoscopic hysterectomy on the other.

The performance of the other level 3 procedures, such as pelvic reconstructive procedures, myomectomy, oncological procedures, and tubal surgery for infertility, remain controversial topics. Besides knowledge of the disease, therapeutic alternatives, indications for surgery, and the options for the surgical approach, these advanced procedures require a much higher level of competence in order to be completed successfully and have a high conversion rate, even in experienced hands [26]. The competence required is much more than the technical surgical abilities necessary for a laparoscopic procedure. In addition, the incidence of these procedures is low and evidence to perform these procedures laparoscopically is still limited or in progress. Therefore, it is appropriate that only experienced, skilled, and qualified (accredited and credentialed) gynecologists in that specialized field should perform these laparoscopic procedures in order to minimize complication rates and to deliver high-quality patient care. Studies have shown that referring is associated with a reduction in rates of excessive blood loss and operating time, and a decreasing trend in visceral injuries [27]. A referral system can be accomplished by establishing a privileging program with a credentialing system and a preceptorship. In this organization, patients can be transferred to referral clinics for that particular field in which expertise in MIS is incorporated. Such a privileging program would include the monitoring of laparoscopic performance, continuing medical education, and the renewal of privileges [5].

\section{Conclusion}

Within the scope of the difficult implementation of advanced gynecological laparoscopic procedures, it is of utmost importance to 'teach the teachers.' In the beginning, a laparoscopic expert can be hired to establish a mentor 
traineeship [17, 18]. If expertise in teaching hospitals becomes sufficient, an increase in caseload and exposure can be expected.

Curriculum guidelines for residency training should consider incorporating advanced procedures, such as laparoscopic hysterectomy. For the other advanced procedures, it is appropriate that only experienced, skilled, and qualified (accredited and credentialed) gynecologists in that specialized field should perform these procedures. A referral system needs to be accomplished by establishing a privileging program with a credentialing system [28]. A high standard of care and adequate implementation can then be expected.

Otherwise, the advanced procedures in laparoscopy will end up like the introduction of the Lichtleiter by Bozzini. His jealous colleagues dismissed the Lichtleiter as a 'mere toy' and the medical faculty in Vienna reprimanded him that the 'Lichtleiter was an undue curiosity.' In the same manner, the attitude of some conventional 'open' operating colleagues will certainly slow down the implementation of laparoscopic surgery in the same manner. To break this ongoing conservatism, there is still work to be done.

Open Access This article is distributed under the terms of the Creative Commons Attribution Noncommercial License which permits any noncommercial use, distribution, and reproduction in any medium, provided the original author(s) and source are credited.

\section{References}

1. Bozzini P (1806) Lichtleiter, eine Erfindung zur Anschaung innere Teile und Krankheiten nebst der Abbildung. J d pract Artznk u Wundartznk 24(204):107-124

2. Cuschieri A, Shapiro S (1995) Extracorporeal pneumoperitoneum access bubble for endoscopic surgery. Am J Surg 170:391-394

3. Johnson A (1997) Laparoscopic surgery. Lancet 349:631-635

4. Kolkman W, Trimbos-Kemper TC, Jansen FW (2007) Operative laparoscopy in the Netherlands: diffusion and acceptance. Eur J Obstet Gynecol Reprod Biol 130:245-248

5. [No authors listed] (1998) Integrating advanced laparoscopy into surgical residency training. Society of American Gastrointestinal Endoscopic Surgeons (SAGES). Surg Endosc 12:374-376

6. Navez B, Penninckx F (1999) Laparoscopic training: results of a Belgian survey in trainees. Belgian Group for Endoscopic Surgery (BGES). Acta Chir Belg 99:53-58

7. Nussbaum MS (2002) Surgical endoscopy training is integral to general surgery residency and should be integrated into residency and fellowships abandoned. Semin Laparosc Surg 9:212-215

8. Kolkman W, Wolterbeek R, Jansen FW (2006) Implementation of advanced laparoscopy into daily gynecologic practice: difficulties and solutions. J Minim Invasive Gynecol 13:4-9

9. Chiasson PM, Pace DE, Schlachta CM, Mamazza J, Poulin EC (2003) Minimally invasive surgery training in Canada: a survey of general surgery. Surg Endosc 17:371-377
10. Royston CM, Lansdown MR, Brough WA (1994) Teaching laparoscopic surgery: the need for guidelines. BMJ 308:10231025

11. Haluck RS, Krummel TM (2000) Computers and virtual reality for surgical education in the 21st century. Arch Surg 135:786792

12. Brölmann HA, Vervest HA, Heineman MJ (2001) Declining trend in major gynaecological surgery in the Netherlands during 1991-1998. Is there an impact on surgical skills and innovative ability? BJOG 108:743-748

13. Schijven MP, Berlage JT, Jakimowicz JJ (2004) Minimal-access surgery training in the Netherlands: a survey among residents-intraining for general surgery. Surg Endosc 18:1805-1814

14. Kolkman W, Wolterbeek R, Jansen FW (2005) Gynecological laparoscopy in residency training program: Dutch perspectives. Surg Endosc 19(11):1498-1502

15. Einarsson JI, Young A, Tsien L, Sangi-Haghpeykar H (2002) Perceived proficiency in endoscopic techniques among senior obstetrics and gynecology residents. J Am Assoc Gynecol Laparosc 9(2):158-164

16. Grantcharov TP, Bardram L, Funch-Jensen P, Rosenberg J (2003) Impact of hand dominance, gender, and experience with computer games on performance in virtual reality laparoscopy. Surg Endosc 17:1082-1085

17. Fowler DL, Hogle N (2000) The impact of a full-time director of minimally invasive surgery: clinical practice, education, and research. Surg Endosc 14:444-447

18. Kolkman W, Engels LE, Smeets MJ, Jansen FW (2007) Teach the teachers: an observational study on mentor traineeship in gynecological laparoscopic surgery. Gynecol Obstet Invest 64:1-7

19. Fabrizio MD, Tüerk I, Schellhammer PF (2003) Laparoscopic radical prostatectomy: decreasing the learning curve using a mentor initiated approach. J Urol 169:2063-2065

20. Chapron C, Devroey P, Dubuisson JB, Pouly JL, Vercellini P (1997) ESHRE guidelines for training, accreditation and monitoring in gynaecological endoscopy. European Society for Human Reproduction and Embryology. Committee of Special Interest Group on Reproductive Surgery. Hum Reprod 12:867-868

21. Härkki-Siren P, Sjöberg J, Kurki T (1999) Major complications of laparoscopy: a follow-up Finnish study. Obstet Gynecol 94:94-98

22. Jansen FW, Kolkman W, Bakkum EA, de Kroon CD, TrimbosKemper TC, Trimbos JB (2004) Complications of laparoscopy: an inquiry about closed- versus open-entry technique. Am J Obstet Gynecol 190:634-638

23. Reznick R, Regehr G, MacRae H, Martin J, McCulloch W (1997) Testing technical skill via an innovative "bench station" examination. Am J Surg 173:226-230

24. Gruber FP, Hartung T (2004) Alternatives to animal experimentation in basic research. ALTEX 21(Suppl 1):3-31

25. Royal College of Obstetricians and Gynaecologists (RCOG) (2001) Classification of laparoscopic procedures per level of difficulty. RCOG, London

26. Rosser JC Jr, Murayama M, Gabriel NH (2000) Minimally invasive surgical training solutions for the twenty-first century. Surg Clin North Am 80:1607-1624

27. Milad MP, Miller D, Shaw S (2000) Comprehensive gynecologic endoscopic hospital privileging program. Implementation and assessment. J Reprod Med 45:365-370

28. Hasson HM, Getzels J (2001) A system of credentialing physicians in advanced gynecologic endoscopy. J Am Assoc Gynecol Laparosc 8:214-217 